\title{
CARTOGRAFIA SOCIAL PARTICIPATIVA DESVELANDO \\ TERRITORIALIDADES NO PACÍFICO COLOMBIANO
}

\author{
PARTICIPATORY SOCIAL CARTOGRAPHY UNVEILING \\ TERRITORIALITIES IN THE COLOMBIAN PACIFIC
}

\section{CARTOGRAFÍA SOCIAL PARTICIPATIVA DEVELANDO TERRITORIALIDADES EN EL PACÍFICO COLOMBIANO}

\author{
Dorival Bonfá Neto ${ }^{1}$ \\ Doutorando pelo Programa de Pós-Graduação em \\ Integração da América Latina (PROLAM/USP). \\ E-mail: dorival.neto@usp.br \\ Orcid: 0000-0001-7570-5441 \\ Júlio César Suzuki ${ }^{2}$ \\ Professor do Departamento de Geografia (FFLCH/USP) e orientador no \\ Programa de Pós-graduação em Integração da América Latina (PROLAM/USP). \\ E-mail: jcsuzuki@usp.br \\ Orcid: 0000-0001-7499-3242
}

\begin{abstract}
Resumo: A cartografia social participativa contribui para a compreensão dos referentes constituídos pelos sujeitos, bem como os significados que os constituem. Assim, com base em oficinas de cartografia social participativa com estudantes do colégio municipal de Bahia Solano, departamento do Chocó, Colômbia, com debates, confecção de mapas e entrevistas, durante trabalho de campo com foco nas atividades pesqueiras artesanais, objetivamos analisar a construção do território e de territorialidades no Pacífico chocoano em relação às práticas e aos saberes tradicionais, muitas vezes ocultos nos mapas oficiais. Percebeu-se, então, que os mapas construídos por crianças e jovens, entre 13 e 17 anos, da comunidade pesqueira de Bahia Solano revelavam a consciência social destes sujeitos, pois em grande medida, eles percebam todas as territorialidades em que estão inseridos e a sua relação com as atividades tradicionais.
\end{abstract}

Palavras-chave: Cartografia social participativa. Território. Pesca. Chocó. Afrocolombianos.

Abstract: Participatory social cartography contributes to the understanding of the referents constituted by the subjects, as well as the meanings that constitute them. Thus, based on participatory social cartography workshops with students from the municipal school of Bahia

\footnotetext{
1 Graduado em Geografia (USP, 2018) e professor na educação básica.

2 Doutor em Geografia Humana pela USP em 2002.
} 
Solano, department of Chocó, Colombia, with debates, making maps and interviews, during fieldwork focusing on artisanal fishing activities, we aim to analyze the construction of the territory and territorialities in the Chocoano Pacific in relation to traditional practices and knowledge, often hidden in official maps. It was noticed, then, that the maps constructed by children and young people, between 13 and 17 years old, of the fishing community of Bahia Solano revealed the social conscience of these subjects, because to a large extent, they perceive all the territorialities in which they are inserted and the its relation to traditional activities.

Keywords: Participative social cartography. Territory. Fishing. Choco. Afrocolombians.

Resumen: La cartografía social participativa contribuye a la comprensión de los referentes constituidos por los sujetos, así como los significados que los constituyen. Así, a partir de talleres participativos de cartografía social con alumnos de la escuela municipal de Bahía Solano, departamento del Chocó, Colombia, con debates, elaboración de mapas y entrevistas, durante el trabajo de campo centrado en las actividades de pesca artesanal, se busca analizar la construcción del territorio y territorialidades en el Pacífico Chocoano en relación con prácticas y conocimientos tradicionales, a menudo ocultos en mapas oficiales. Se advirtió, entonces, que los mapas construidos por niños y jóvenes, entre 13 y 17 años, de la comunidad pesquera de Bahía Solano revelaron la conciencia social de estos sujetos, pues en gran medida perciben todas las territorialidades en las que se insertan y la su relación con las actividades tradicionales.

Palabras Clave: Cartografía social participativa. Territorio. Pesca. Choco. Afrocolombianos.

Data de recebimento: $02 / 11 / 2020$

Data de aprovação: 20/12/2020

\section{1 - INTRODUÇÃO}

Onde quer que haja mulheres e homens, há sempre o que fazer, há sempre o que ensinar, há sempre o que aprender. (Paulo Freire).

Idealmente, a educação é um lugar onde a necessidade de diversos métodos de ensino é valorizada, estimulada e vista como essencial para o aprendizado. (Bell Hooks, Ensinando a transgredir, 2017, p.268).

A cartografia social participativa é uma mediação fundamental na identificação de referentes espaciais e na atribuição de significados, pois se refere à construção coletiva de informações geoespaciais a partir de instrumentos técnicos de mediação, além de mapas mentais, dentre outras possibilidades, conforme assegura Marcos Aurélio Pelegrina (2020).

Assim, com base em oficinas de cartografia social participativa com estudantes do município de Bahia Solano, departamento do Chocó, Colômbia, com debates, confecção de 
mapas e entrevistas, durante trabalho de campo com foco nas atividades pesqueiras artesanais, objetivamos analisar a construção do território e de territorialidades no Pacífico chocoano em relação às práticas e aos saberes tradicionais, muitas vezes ocultos nos mapas oficiais.

Trilharemos, em nossa discussão, pela análise da experiência de oficinas de cartografia social participativa, realizadas no município de Bahia Solano, departamento do Chocó (Colômbia), iniciando com a caracterização da região do Pacífico Colombiano e do departamento do Chocó e seguindo com a constituição do território e de territorialidades relativos à pesca, com foco na demonstração da cartografia social participativa como mediação reveladora das territorialidades relacionadas com as práticas tradicionais, em específico, com a pesca artesanal, assim servindo como uma ferramenta para a proteção e (re)apropriação do território tradicional.

Para a compreensão do território e das territorialidades da pesca tradicional, marcadamente praticada por afrodescendentes, no município de Bahia Solano, foi realizado trabalho de campo, pautado por observação participante e entrevistas com base em roteiro semi-estruturado, com captura de testemunhos sobre a atividade e as práticas sociais de reprodução material e imaterial, com foco em praticantes da pesca artesanal, entre os dias 14 e 31 de janeiro de 2020 .

O trabalho de campo, ainda, foi enriquecido pela composição de séries fotográficas, conversas com moradores não-pescadores, caminhadas pelo território e realização cinco oficinas no colégio da sede municipal (cabeceira municipal) de Bahia Solano, foco da nossa análise.

As oficinas possibilitaram discussões com crianças e jovens da comunidade acerca do significado do ofício pesqueiro na cultura e na economia local, como mediação para capturar as distintas leituras que eles possuem em relação à pesca e ao mar. Para tanto, foram elaborados mapas sociais participativos, em que diversas informações não documentadas fossem relatadas, a partir da vivência e percepção dos sujeitos.

Os mapas, então, aparecem como ferramenta para indicar quais territorialidades são permeadas e construídas pelos conhecimentos simbólicos e populares e pelas atividades tradicionais (ACSERALD; COLI, 2008), sobretudo pela principal delas, a pesca artesanal, demonstrando que o território se constrói e é apropriado em conjunto com o modo de vida, a partir da relação entre a cultura e o espaço. Entende-se, portanto, que o território não se constitui apenas pelas fronteiras e pelo controle ou poder, mas também pela relação cultural e social que os grupos estabelecem com o lugar a partir de seus modos de vida (SUZUKI, 2013), suas práticas cotidianas e suas identidades (SAQUET, 2015).

As oficinas realizadas foram embasadas por uma pedagogia da resistência, uma pedagogia anticolonial, com o intuito de conscientizar os sujeitos de suas ações e da importância de seus saberes tradicionais e populares e de seus territórios. Dessa forma, impôs-se necessário conhecer os aluno e a comunidade, como propõe Bell Hooks (2017), o que nos conduziu para a valorização da presença e do conhecimento de cada um dos estudantes do colégio, buscando valorizar " [...] a experiência de aprender quando nossas experiências são consideradas centrais e significativas” (HOOKS, 2017, p.53). 


\section{2 - O PACÍFICO COLOMBIANO}

O Pacífico colombiano possui uma área de $116.000 \mathrm{~km}^{2}$ e uma extensão de norte a sul de 1.495km (DÍAZ; GALEANO, 2016), contendo quatro departamentos (Chocó, Valle del Cauca, Cauca e Nariño) e 15 municípios, sendo Bahia Solano, Tumaco e Buenaventura são os principais (DEFENSORIA DEL PUEBLO, 2016). Mais de 90\%, do total aproximado de 650.000 habitantes da zona costeira (a maioria afrodescendentes), vivem nos cascos urbanos dos municípios de Tumaco, Buenaventura e Bahia Solano, onde estão também as principais atividades comerciais e de serviços da região (DÍAZ; GALEANO, 2016).

Para Julio Carrisoza Umaña (2014), a região do Pacífico colombiano trata-se de um Sistema Ambiental Territorial, conceito que se fundamenta em um pensamento complexo, e "[...] que reúne los elementos bióticos y abióticos no humanos con los humanos (UMAÑA, 2014, p.126)". Para o autor, a Colômbia é um país formado por "conglomerados territoriais", em que a região do Pacífico trata-se de um. Os conglomerados territoriais são "[...] generados en Colombia por las interrelaciones entre lo imaginario, la gente y la realidad de la estructura física y biótica." (UMAÑA, 2014, p.125).

Arturo Escobar (2015) chama a região de Pacífico Biogeográfico, expressão que traz a ideia de uma região constituída por processos históricos que implicam as dimensões geológicas, biológicas, políticas e socioculturais. Para Escobar, até fatores como a geologia, a geomorfologia e o ecossistema, são também constituidores de processos históricos, em uma visão complexa pela qual "[...] la historia no solo es uma propriedade de lo humano y los processos biológicos ('evolución') sino también de lo físico y lo químico" (ESCOBAR, 2015, p.54).

A região trata-se de uma das mais remotas do país, principalmente na parte norte ou no departamento do Chocó, o departamento mais ao norte do Pacífico colombiano, fazendo fronteira ao sul com o Departamento Valle del Cauca e ao norte com o Panamá. O Departamento do Chocó possui 30 municípios, 457.412 habitantes e uma área de $46.530 \mathrm{~km}^{2}$, com densidade demográfica aproximadamente de 9,8 habitantes por $\mathrm{km}^{2}$, sendo considerado o departamento mais pobre do país (DANE, 2019). 


\section{Figura 1 - O Pacífico Colombiano}

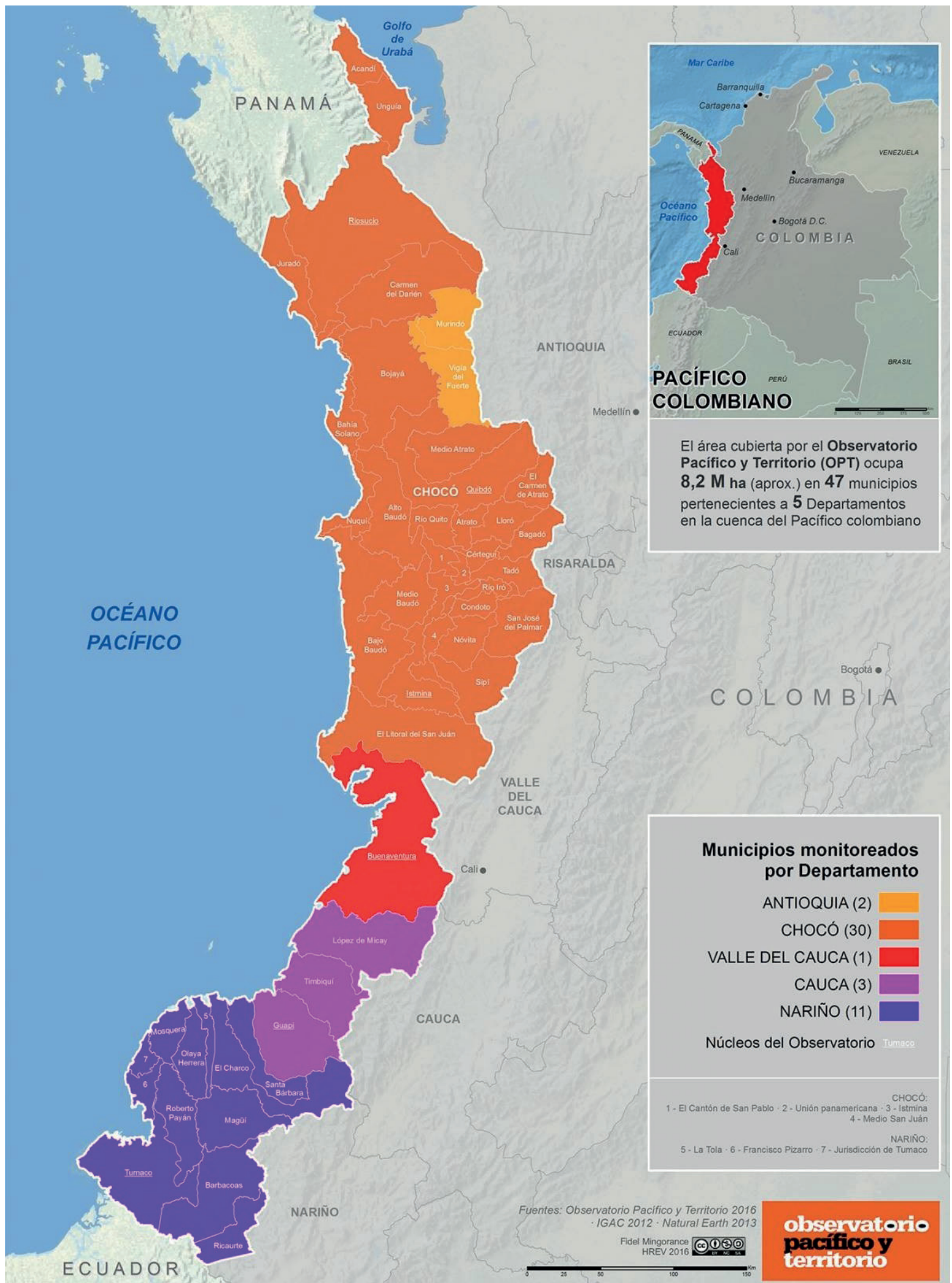

Fonte: Observatorio Pacífico y territorio (2016). Disponível em: $<$ https://pacificocolombia.org/pacifico-colombiano/>. Acesso em 03/11/2020. 
A região é ocupada de maneira dispersa, por cidades de pequenos portes, praias e corregimentos (aglomerações urbanas menores que a sede municipal ou "cabecera municipal") e seus habitantes se apoiam em costumes ancestrais, que lhes possibilitaram uma coexistência com algumas condições mais extremas do mar e da floresta, como a extrema umidade que pode chegar a $12.000 \mathrm{~mm}$ anuais.

No Pacífico Biogeográfico, há pequenas comunidades e povoados de pescadores, em sua grande maioria formados por afrocolombianos, mas também por habitantes de diversas origens étnicas indígenas, das que resistiram e permaneceram após a invasão europeia, como os embera-katío, wuanam e kuna, além de outros oriundos dos diversos fluxos populacionais para a região ${ }^{3}$ UMAÑA, 2014).

Toda essa diversidade cultural e socioambiental só se faz possível a partir da manutenção dos múltiplos territórios existentes como um elemento determinante para a reprodução material e imaterial do modo de vida das sociedades afrocolombianas e indígenas, baseados na pesca, na agricultura e no extrativismo. Sendo assim, o modo de vida se realiza como forma de apropriação e reprodução social em que se inserem os sujeitos, e em suas múltiplas relações tecidas com o ambiente, que serão elementos determinantes na produção de seus territórios e suas territorialidades (SAQUET, 2015; SUZUKI, 2013).

\section{3 - TERRITÓRIO E TERRITORIALIDADES}

O território afrocolombiano é o instrumento pelo qual essa sociedade se apropria do mundo, transformando e o protegendo, como elemento necessário para sua sobrevivência, sendo que, como conceito, passou a ser utilizado na região pelos ativistas e pelos movimentos sociais locais a partir da década de 1980, quando a região do Pacífico Biogeográfico passou a ser ameaçada por megaprojetos de desenvolvimento (portos, atividade mineradora, pesca industrial, extrativismo vegetal, etc.), gerando a iminência de desestruturação das territorialidades das comunidades afrocolombianas. Assim, a existência e a resistência destes territórios ocorrem em relação à construção de uma identidade por parte dos grupos negros do Pacífico, que culmina na promulgação da Lei 70, de 1993, que garante a titulação coletiva das terras baldias para os afrocolombianos (ESCOBAR, 2015). O território desses grupos une o passado e o presente, ou seja, manifesta diferentes temporalidadades e territorialidades que precisam ser defendidas:

Brevemente, el territorio se considera como un espacio fundamental y multidimensional para la creación y recreación de las prácticas ecológicas, económicas y culturales de las comunidades, él une pasado y presente. En el pasado, las comunidades mantuvieron la autonomía relativa así como las formas de conocimiento y estilos de vida conducentes a ciertos usos de los recursos naturales; en el presente, existe la necesidad de su defensa. (ESCOBAR, 2015, p.181).

3 Por exemplo, os escravizados foragidos das fazendas de mineração de ouro, chamados de cimarrones, e, durante o século $\mathrm{XX}$, dos paisas, provenientes do Departamento de Antioquia, mas também de pessoas vindas de outros departamentos, como de Tolima e Boyacá. 
A união de diversos tempos, ou temporalidades confirma que os territórios, as territorialidades e as temporalidades são capazes de demonstrar relações, contradições, diversidades, conflitualidades e unidades que nos ajudam a orientar as pesquisas, os projetos e os planos a partir das necessidades e desejos dos sujeitos, grupos e classes sociais, o que faz do território multidimensional, tal qual afirma Saquet (2015), o que nos permite considerar a produção de territorialidade como sendo:

[...] as relações diárias, momentâneas e processuais, que os homens mantêm entre si, com sua natureza interior e com sua natureza inorgânica para sobreviverem biológica e socialmente. A territorialidade é o acontecer de todas as atividades cotidianas, seja no espaço do trabalho, do lazer, da igreja, da família, da escola, da rua, do bairro, resultado e determinante do processo de produção de cada território no movimento mais amplo de TDR [Territorialização-Desterritorialização-Reterritorialização]. 2015, p. 120).

(SAQUET,

Os grupos afrocolombianos, então, possuem territorialidades próprias constituídas por três níveis, dos quais trata Saquet (2015): da vida social, vida não humana (animal e vegetal) e do domínio espiritual. Tal compreensão está em consonância com a concepção de território utilizada por ativistas da região, movimentos sociais e alguns autores, como Escobar (2015), em que a biodiversidade é mediação da conformação territorial e da cultura.

Para os ativistas que atuam junto aos grupos afrocolombianos do Chocó, a biodiversidade é resultado do território mais a cultura (ESCOBAR, 2015), ou seja, não há conservação da natureza sem controle territorial, bem como a conservação não pode existir de maneira alheia às práticas tradicionais das populações locais. Por exemplo, é comum os habitantes locais apontarem a perda de valores tradicionais como um dos primeiros fatores que causam a redução da biodiversidade e a degradação dos ambientes. Além disso, a identidade e a territorialidade dos grupos afrocolombianos do Pacífico (que se construíram em paralelo, durante as décadas de 1980 e 1990) estão ancoradas no espaço aquático (rio e mar).

Nesse sentido de discussão dos territórios negros no Pacífico Biogeográfico, a cartografia social participativa nos permite identificação de quais são as territorialidades essenciais para a reprodução do modo de vida dos afrocolombianos, as quais não aparecem nos mapas convencionais (ACSERALD; COLI, 2008).

Este sub-campo da cartografia participativa constitui o domínio social delimitado por premissas institucionais, culturais e cognitivas, onde atores sociais orientam estrategicamente suas ações disputando legitimidade no âmbito das representações espaciais. [...] constroem-se fronteiras simbólicas, técnicas e morais com relação a outras práticas organizadas, configurando certa perícia legitimada, redes inter-pessoais e organizacionais, distribuição de recursos e regras internas de jogo. Tendo como referência o campo da produção cartográfica. (ACSERALD; COLI, 2008, p.17). 
Portanto, os mapas e a política de mapeamento tradicional estabelecem disputas entre as distintas representações do espaço, assim articulando as disputas e conflitos territoriais com a disputa cartográfica (ACSERALD; COLI, 2008), o que se coloca para nós, em nossa análise, como posição política a do uso da cartografia social participativa, já que legitima (mais ainda) a ocupação e apropriação do espaço pelos afrocolombianos, como existência e resistência.

\section{4 - OFICINAS E CARTOGRAFIA SOCIAL PARTICIPATIVA NO COLÉGIO: METODOLOGIA E RESULTADOS}

Foram realizadas cinco oficinas no colégio da sede municipal de Bahia Solano, Instituición Educativa Luis López de Mesa, que abrange os períodos $6^{\circ}, 7^{\circ}, 8^{\circ}, 9^{\circ}, 10^{\circ}$ e $11^{\circ}$ (os seis últimos anos da educação básica na Colômbia), com o acompanhamento do professor Sebastian Rivera.

O colégio concede o grau de "Bachiller técnico em ciências del mar", por isso, conta com algumas disciplinas (asignaturas ou cátedras) específicas, relacionadas à realidade local: a) Hombre, mar y sociedad; b) Marinería; c) Navegación marina; d) Oceanografía; e) Recursos vivos marinos; f) Artes y métodos de pesca.

Durante a apresentação das oficinas e conversa prévia com os alunos, a grande maioria dizia ser parente próximo ou amigo de pescadores ou pescadoras, demonstrando que quase todos possuíam uma grande familiaridade com a atividade.

As oficinas foram realizadas entre os dias 22 e 31 de janeiro de 2020 . A primeira foi realizada, no dia 22 de janeiro de 2020 , com os alunos da turma $10^{\circ} \mathrm{B}$ (idades entre 14 e 16 anos). A segunda oficina foi realizada, no dia 23 de janeiro de 2020 , com os alunos do $11^{\circ} \mathrm{B}$ (último ano da educação básica na Colômbia), que tinham uma faixa etária de 15 a 18 anos. A terceira oficina foi realizada, no dia 29 de janeiro de 2020 , com os alunos do $11^{\circ} \mathrm{A}$ (idades entre 15 e 17 anos). A quarta oficina foi realizada, no dia 30 de janeiro de 2020, com os alunos do período $9^{\circ} \mathrm{C}$ (idades entre 13 e 16 anos). No dia 31/01/2020, realizamos a última oficina com os alunos do $6^{\circ} \mathrm{B}$ (idades entre 10 e 13 anos), sendo que, em todas as oficinas, os alunos formaram grupos com quatro a seis participantes para a realização das atividades, conversas e debates que eram propostos.

A oficina se iniciava, sempre, com a formação dos grupos, seguida da nossa apresentação como tutor, em que se contava um pouco da nossa trajetória pessoal e acadêmica, das razões de se estar em atividade de pesquisa em Bahia Solano e sobre as diferenças e semelhanças entre o Brasil e a Colômbia, com o intuito de iniciar o diálogo com os alunos, gerar empatia e estabelecer um vínculo de confiança. Em seguida, as cinco questões propostas foram duplicadas em 10 folhas e distribuídas de duas em duas a cada grupo, tendo sido encontradas respostas como as que seguem:

1) ¿Cuál es la importancia del mar?

"Para nosotros la importancia que tiene el mar, es que es la fuente más importante para nosotros los costeños, ya que muchos dependemos de él. 
Nos ofrece muchos recursos tales como el transporte, la pesca, el buceo, la extracción de sal entre muchos otros, entre si los recursos que nos ofrece el mar son infinitos. En conclusión, el mar nos ensena todo lo que somos nosotros los costeños tanto cultural como económicamente." (alunos $10^{\circ} \mathrm{B}$ ). "La importancia del mar es que hay una gran diversidad de peces la cual sirven como alimentos para nosotros y peces también. Es el hábitat de muchos peces los ayuden a protegerse. El mar también es importante porque con el podemos aprender más sobre los seres acuáticos." (alunos $10^{\circ} \mathrm{B}$ ).

"Es muy importante ya que es uno de los recursos más necesarios a nivel mundial que nos brinda la naturaleza, ya que desde el comienzo de la humanidad se ha utilizado como medio de transporte, alimentación, comercio, rutas turísticas, culturales, y ha sido fuente de descubrimientos de 'nuevos mundos'." ( alunos $\left.11^{\circ} \mathrm{B}\right)$.

"El mar es muy importante porque es el ecosistema más grande que tenemos está lleno de animales marinos y también es importante porque le brinda beneficios al hombre y nos benefician con su riqueza en peces...que además nos brinda una gran bioversidad."( alunos $9^{\circ} \mathrm{C}$ ).

"La importancia del mar para nosotros seria los peces todos los animales marinos (la sierra el atún robalo las ballenas o sea lo más importante del mar es lo salado" (alunos $6^{\circ} \mathrm{B}$ ).

2) ¿Cuáles son los beneficios de la pesca artesanal?

"Nos brinda trabajo mediante la pesca, podemos vender el pescado y ensenarle a pescar a otras. Vendiendo el pescado pudimos comprar otras cosas y obtener dinero. Con la pesca artesanal podemos obtener alimento." (alunos $10^{\circ} \mathrm{B}$ ).

"Se obtienen especies marinas aptas para el consumo y la comercialización humana la cual trae muchos beneficios para los pescadores, comerciantes compradores y terciarios." ( alunos $11^{\circ} \mathrm{B}$ ).

"Los beneficios de la pesca artesanal principalmente se basa en la alimentación, en el comercio nacional e internacionalmente por lo tanto hay muchas personas que basa su vida de esa forma de pesca por lo cual ayuda a la vida diaria." (alunos $11^{\circ} \mathrm{A}$ ).

"Es una actividad que puede aprender de primera mano el turismo marinero es la calidad y de una forma sostenible sobre largar el esfuerzo pesquero por ejemplo: trasnocharse lleva aguacero y también lleva mucho sol en algunas ocasiones etc. y los beneficios que nos traen son: la plata, la comida, la ropa y estudio de sus hijos." (alunos $9^{\circ} \mathrm{C}$ )

"Los beneficios de las pesca artesanal son: que nos trae los pescados, la pesca artesanal es bueno para coger pescados y recibir alimentos para los que aguantan hambre." (alunos $6^{\circ} \mathrm{B}$ ).

3) ¿Conocen de las fases de la luna según los pescadores?

"Se conoce según los pescadores que cuando se encuentra en luna llena podemos obtener abundancia de muchos peces, porque con las fases de la luna se otorgan los cambios de marea, es decir, esto ayuda a que hallo una buena faena de peces." (alunos $10^{\circ} \mathrm{B}$ ).

"Según los pescadores cuando la luna está llena hay una disminución de peces, cuando la luna está en menguante la pesca esta normal." (alunos 
$\left.11^{\circ} \mathrm{B}\right)$.

"LUNA LLENA: No se puede realizar la pesca artesanal porque en esa etapa del ciclo de la luna hay mucha claridad, y la marea comienza a crecer hasta el punto más alto. MEDIA LUNA: En esta fase de la luna la marea empieza quebrar (ya no hay puja) y la pesca artesanal comienza a producir más pescado en ciertas partes dos de ellas son Cabo Marzo y Punta Piña. QUARTA MITAD: En esta fase de la luna se realiza más constante porque no hay casi luz en el mar y los pescadores a aprovechan esa etapa. MENGUANTE: En esta fase ya la luna quiebra del todo y por lo tanto hay es donde la pesca mejora demasiado, y el pescado está más abundante porque no hay tanta luz."(alunos $9^{\circ} \mathrm{C}$ ).

4) ¿Que conocen de la pesca artesanal?

"La pesca artesanal es un método donde se pesca a mano o con vara de pescar, con uno empatamiento, como el anzuelo, el nilón plomado, cebo o carnada de pesca." (alunos $10^{\circ} \mathrm{B}$ ).

"Es la forma de pesca que se utiliza en la ZEPA." (alunos $11^{\circ} \mathrm{A}$ ).

"La pesca artesanal es aquella que desempeñan to ${ }^{4}$ dos los pescadores costeños del país, se dice artesanal porque los instrumentos utilizados para hacer esta actividad son creados por los mismos pescadores." (alunos $11^{\circ} \mathrm{B}$ ). "En la pesca artesanal se utilizan muchos instrumentos de pesca como: el anzuelo, el Plomo, Trasmallo, Boyas, La atarraya etc." (alunos $9^{\circ} \mathrm{C}$ ).

5) ¿Como la pesca artesanal está en la manera de vivir de Bahía Solano y del Chocó?

"La pesca artesanal es la manera de vivir de nuestro municipio ya que es nuestro alimento y lo podemos exportar a otras ciudades de nuestro país." (alunos $11^{\circ} \mathrm{A}$ ).

"Gracias al territorio donde nos encontramos que nos brinda el mar con los peces nos sustentamos de manera económica y de mucha alimentación por medio de la pesca artesanal y por medio de ella hay en día hoy grandes empresas que se benefician de las riquezas que nos brinda el pescado favoreciendo a ellos ya a nosotros." (alunos $10^{\circ} \mathrm{B}$ ).

"Una de las formas de ingreso en el municipio de Bahía Solano y departamento del Choco, y le genera a la comunidad chocoana." (alunos $10^{\circ} \mathrm{B}$ ).

"La pesca artesanal está en la manera de vivir en Bahía Solano y en el Chocó ya que es una actividad tradicional que se nos facilita a los habitantes debido a la relación que tenemos el mar y el hombre. En las cuales tenemos las siguientes: nos brinda la alimentación, el transporte, y nos ayuda mucho en la parte económica." (alunos $10^{\circ} \mathrm{B}$ ).

"El pescado es uno de los productos que hacen parte de nuestra cadena alimentaria y nos brinda muchos beneficios a nivel de salud. Gracias a estos beneficios muchos pescadores viven de su labor ya que además de pescar para su alimentación pescan para vender el producto para suplir otras necesidades diarias." (alunos $11^{\circ} \mathrm{B}$ ).

"Está en la parte tanto económica y social ya que hace ver la humildad de cada familia, lo trabajador sostiene la manera de vivir ya que el comercio y la economía la tienen como base, de esta se refleja la cultura de los habitantes, también la relación entre lo exterior e interior del país, ya que Bahía solano

$4 \quad$ ZEPA é a Zona Exclusiva de Pesca Artesanal, uma área protegida marinha criada em 2013 para uso exclusivo da pesca artesanal, permitindo somente a pesca de linha e espinhel (DÍAZ; CARO, 2016). 
es uno de los exportadores más grandes del país." (alunos $11^{\circ} \mathrm{B}$ ).

"La pesca artesanal en la forma de vivir de Bahía Solano y el Choco para mucho es un trabajo como cualquier otro marca identidad en nuestro medio es una forma de generar ingresos es pasión las persona se apasionan de las cosas que hacen y de lo que les guste o marque en un punto de su vida en el Choco la pesca artesanal nos identifica es lo que hacemos muchos crecemos y regresamos con ayuda de esta."(alunos $11^{\circ} \mathrm{B}$ ).

"La pesca artesanal sirve como un sustento que influye en la economía del Pueblo y dado que los pescadores después de atraparlos los venden y los compradores los exportan y eso genera ingreso al Pueblo." (alunos $11^{\circ} \mathrm{B}$ )

"La pesca artesanal de Bahía Solano se basa más que todo en lo económico y cultural, nosotros los pescadores artesanales nos beneficiamos del mar tanto económicamente y también para nuestro suministros personales." (alunos $\left.9^{\circ} \mathrm{C}\right)$.

"La pesca artesanal se considera una tradición en el Choco que es realizada en el mar y es una manera de alimento y es una función realizada para atrapar los peces." (alunos $9^{\circ} \mathrm{C}$ ).

"La pesca artesanal es en la manera de que los pescadores utilizan esta actividad para tener una forma de vida mejor porque ellos y sus familiares a través de esta actividad ellos tienen mucho conocimiento en como agarran un pescado en qué formas pescar y obtener una gran cantidad de peces. Los Barrios de Bahia Solano que tienen más pescadores es Barrio Nuevo y Chambacu. Así mismo el su forma de vida de los chocoanos porque ellos en su mayoría tienen muchos pescadores" (alunos $9^{\circ} \mathrm{C}$ ).

"La pesca artesanal es muy importante es la manera de vivir de los chocoanos y solaneños ya que gracias a esta pesca se consigue un mineral muy importante que son los peces." (alunos $9^{\circ} \mathrm{C}$ ).

"La pesca artesanal está en la manera de vivir porque conjuntos pescados para recibir los alimentos que necesitamos."(alunos $\left.6^{\circ} \mathrm{B}\right)$.

Entre as respostas dos alunos e ao final de todos os grupos exporem as suas respostas, eram feitas intervenções em que foram pontuadas a importância social e cultural, econômica, ecológica e de segurança alimentar que a pesca artesanal possui, bem como as maneiras pela qual a atividade encontra-se intimamente ligada com a população. Os alunos iam complementando e debatendo as informações que estavam sendo expressas. Durante esses períodos, muitos jovens iam se manifestando dizendo que o pai, o tio, ou outros familiares eram pescadores e que haviam aprendido algumas dessas coisas com eles, enquanto muitos outros diziam ter aprendido na escola (com as disciplinas específicas do enfoque em ciências do mar, que o colégio possui), e muitos alunos também, quase que exclusivamente homens, diziam já praticar a pesca de maneira lúdica, tendo realizado algumas pescarias curtas com os familiares ou conhecidos.

Após esse momento, eram passados dois vídeos explicando sobre a ZEPA e sobre a pesca em Bahia Solano5. Por fim, foi proposto aos alunos fazerem mapas que pudessem

5 Os dois vídeos estão disponíveis no Youtube, no canal Conservación Internacional Colombia, e eram intitulados ZEPAZona Exclusiva de Pesca Artesanal. Disponíveis em: $<$ https://www.youtube.com/watch?v=MiyS_B201YA $>$ e $<$ https:// www.youtube.com/watch?v=QFppUa1MgrQ $>$. Acesso em 30/10/2020. 
demonstrar como a pesca estava presente no modo de vida de Bahia Solano, bem como ressaltando a territorialidade pesqueira. Como ponto de partida, foram feitos alguns questionamentos, entre os quais: “¿Quién es el pescador?, ¿Cómo veen la comunidad a los pescadores?, ¿Cuáles son los aportes del pescador artesanal a la comunidad?, ¿Cómo la pesca está en lo modo de vida de los solaneños?, ¿Cuál es el circuito de la pesca?, ¿Cuáles son los territorios donde la pesca esta? e ¿Cuáles son los desafíos y los problemas de los pescadores?”.

Os desenhos puderam demonstrar visões sobre os lugares onde mais se manifestavam e qual era a abrangência da territorialidade da pesca artesanal, cujas informações eram condizentes com a percepção que tivemos durante os levantamentos de campo.

Em todos os desenhos, foram ressaltados os territórios da margem do Rio Jella (Ponte de Chambacu), a Red de Frio e a Merluza Pesquera (locais onde comercializam os pescados), além do mar, dos corregimentos e dos pontos (sítios) de pesca. Dessa forma, por meio dos desenhos ficou explícita a territorialidade da pesca artesanal e como esta está presente no modo de vida de todos do município. Seja realizando o ofício, conhecendo alguém que o realiza, tendo uma pessoa na própria casa que o realiza, ou, mesmo, por meio do colégio e de suas disciplinas específicas com ênfase em ciências do mar, que faz com que os alunos já tenham um contato prévio com os saberes do mar, e muitas vezes esse contato é aprofundado pelas vivências na comunidade, sendo que os alunos, quando questionados se aprendiam mais de pesca nas aulas no colégio ou na prática e vivência, a grande maioria respondia ser fora do espaço de ensino regular.

\section{5 - RESULTADOS DAS OFICINAS DE CARTOGRAFIA PARTICIPATIVA E CONTEXTUALIZAÇÃO DOS MAPAS}

Na figura 2 está o Oceano Pacífico e aparentemente um turista tirando foto de um golfinho que salta no mar. O interessante dessa representação de paisagem é notar as frases escritas pelos alunos como "La dedicación y la observación hacen un buen pescador", dando a entender também que a pessoa pode ser um pescador, e não um turista (apesar da roupa), mas também expressando como a pesca é algo que se aprende mais na prática, por meio da observação, tentativa e da vivência, do que pela teoria. Isso demonstra uma consciência dos alunos para com esse processo de que os conhecimentos da pesca são de fato tradicionais e empíricos. 
Figura 2 - Mirador del parque hacia playa

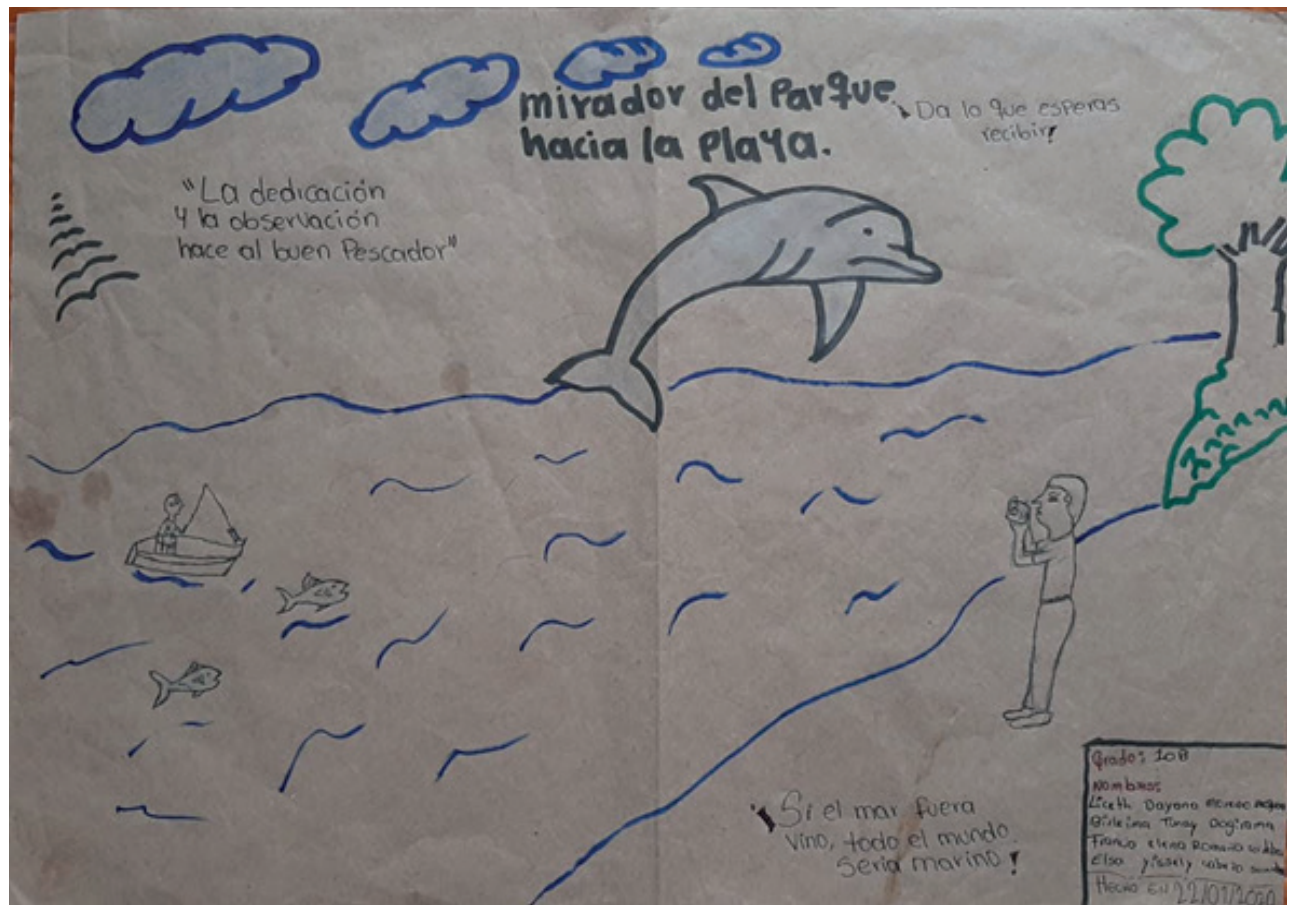

Fonte: Trabalho de campo (2020), elaborado pelos alunos do $10^{\circ} \mathrm{B}$, Liceth Dayana Moreno, Birleima Tunay Dogirama, Francia Elena Romaña Cordoba, Elsa Yissely Cabeza, em 22/01/2020.

Figura 3 - Distribución de la pesca artesanal por lo Rio Jella

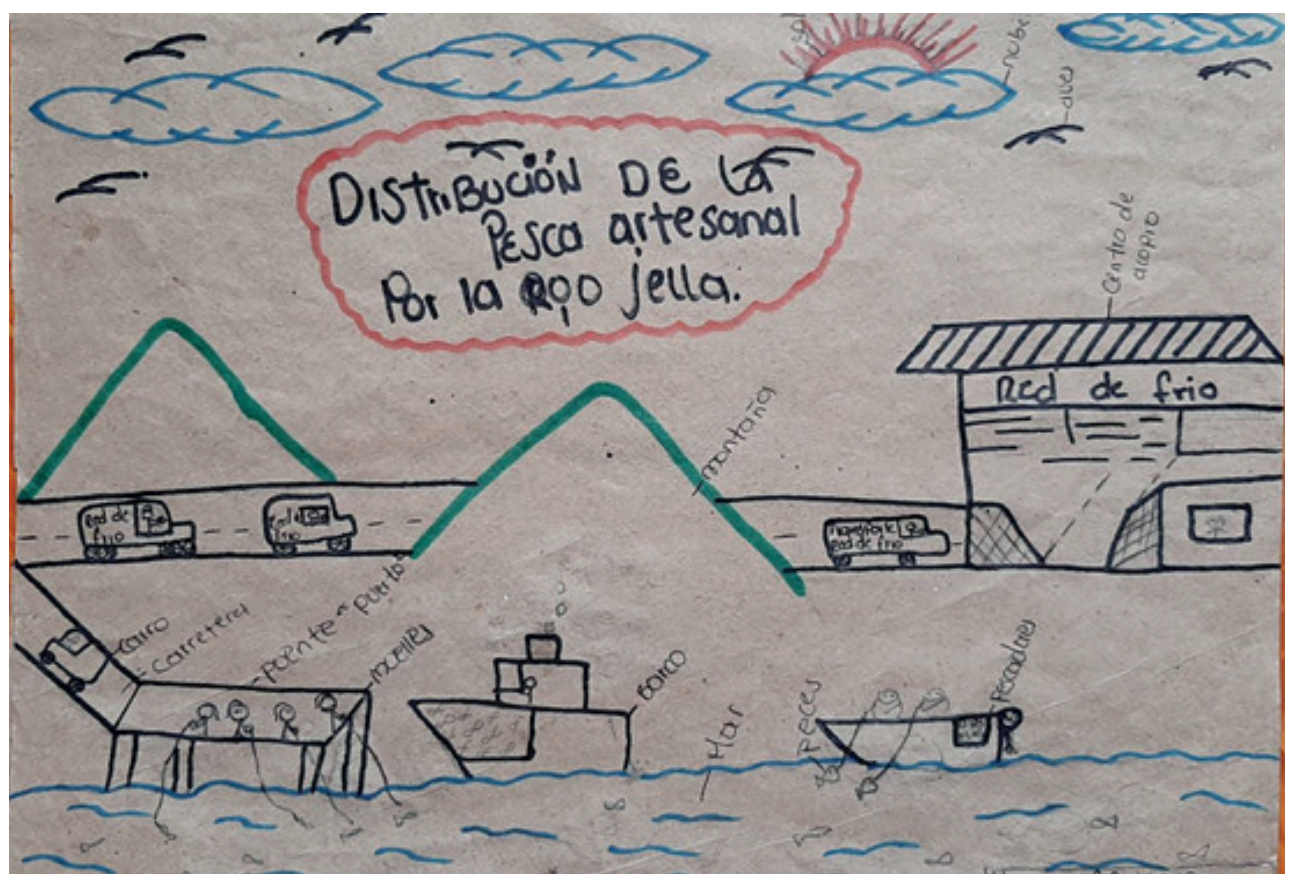

Fonte: Trabalho de campo (2020), elaborado pelos alunos do $10^{\circ} \mathrm{B}$, Xiary Yussaira Girón Mosquera, Amanda Yaiiana Coban Gamboa, Yellen Bermudez, Santiago Olaya Riasco, Elkin Valoyes Renteria, no dia 22/01/2020. 
A paisagem, representada na figura 3, demonstra o Rio Jella com uma lancha chegando com outra lancha maior. Um fato curioso é que há o desenho de mulheres pescando na ponte, demonstrando a presença feminina na atividade. Há também a estrada constando o transporte dos pescadores (nos três carros desenhados está escrito Red de Frío, a cooperativa de pescadores que faz o comércio).

A figura 4 é a que representa uma escala geográfica maior (portanto, uma menor escala cartográfica), dentre todas as representações realizadas pelos alunos, abrangendo toda a área da ZEPA (desde Punta Ardita (ao norte), divisa com o Panamá, até o limite de Nuqui com o PNN Utria (ao sul).

Figura 4 - Rutas de pesca artesanal en el Pacífico Norte

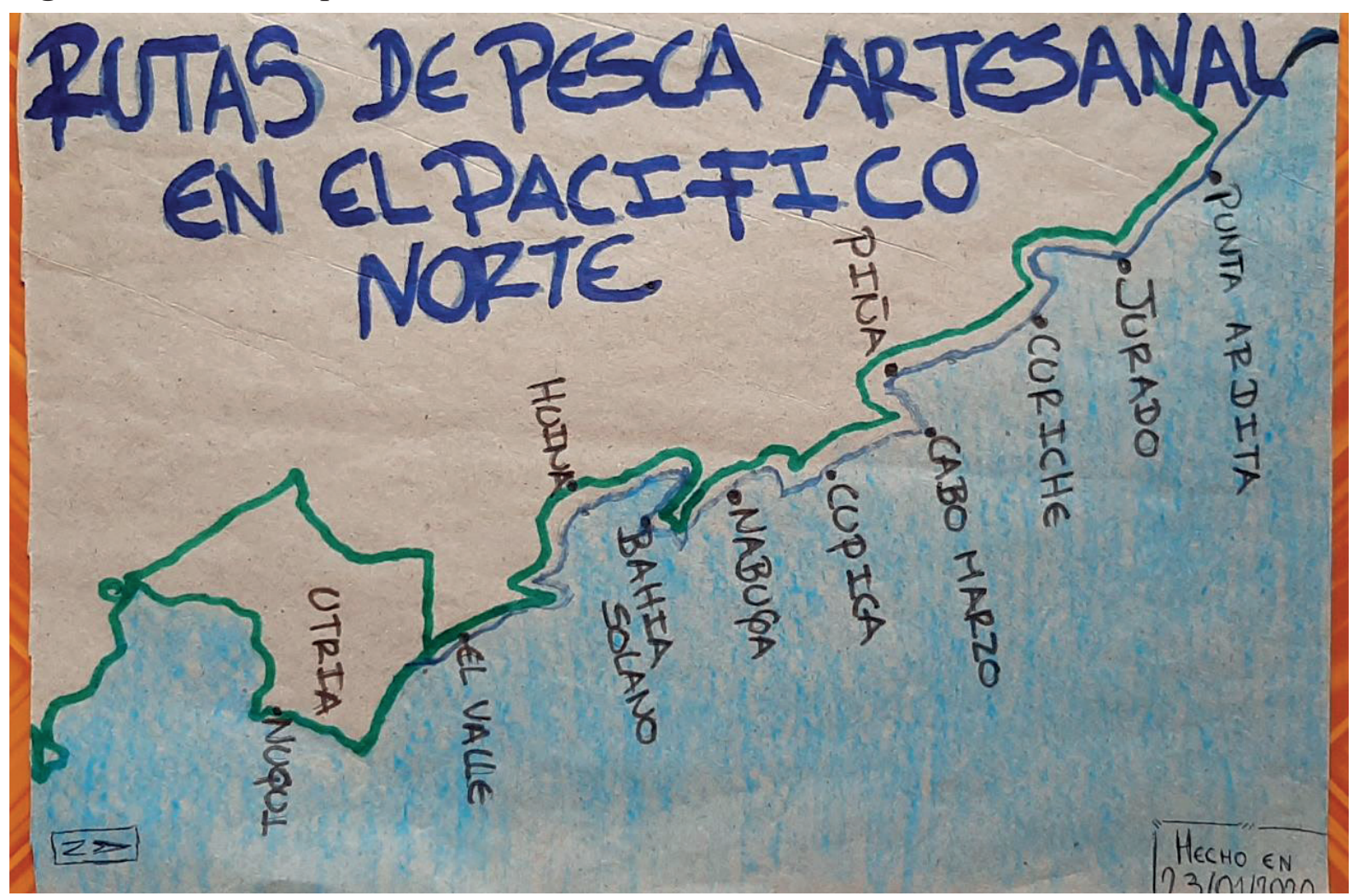

Fonte: Trabalho de campo (2020), elaborado pelos alunos do $11^{\circ} \mathrm{B}$, Natalia de Hoyos, Qely Andrea Rios, Thalia Ruiz Cordoba, Natalia Velasquez Alvarez, em 23/01/2020. 
Figura 5 - Zonas de Pesca en Bahia Solano

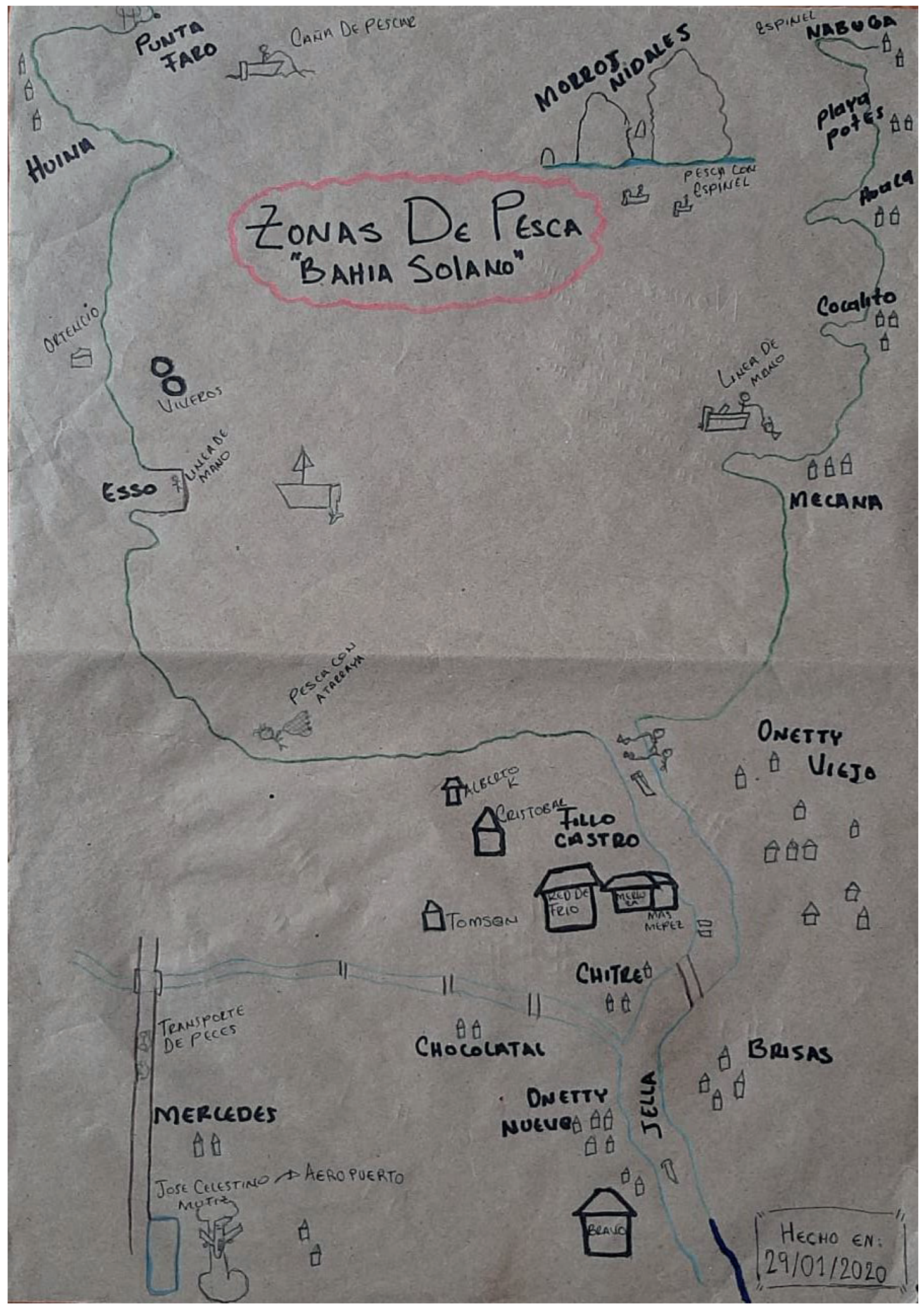

Fonte: Trabalho de campo (2020), elaborado pelos alunos do $11^{\circ} \mathrm{A}$, Andres Camilo Ruiz Badillo, Yurleisy Moreno Castillo, Ferney Valois Todro, Yamile Cordoba Arias, Alex Yesin Leon Asprilla, Luisa Maria Polo Castillo, Paula Potes Vallois, em 29/01/2020. 
É um dos mapas (figura 5) que mais capta os territórios de pesca de uma maneira abrangente, porém sem perder as especificidades de cada lugar, praia e corregimento, demonstrando exatamente o trajeto das pescarias que realizamos durante a nossa observação participante em Bahia Solano. No canto superior esquerdo, está o Aeroporto, seguido do caminho para a cidade e cruzando com o Rio Chocolatal. Mais ao canto inferior direito do desenho está o Rio Jella e os bairros ao seu redor (Onetti Novo e Onetti velho, este popularmente chamado de Chambacu, por ser um bairro de pescadores). É identificada a ponte de Chambacu com as redes de comercialização ao redor (Masmepez, Red de frio e Merluza Pesquera). Há também representação das pesqueiras de Cristobal e Alberto. Logo na margem da praia de Bahia Solano, há um pescador coma tarrafa, e no posto Esso um pescador com linha de mão, mas, acima, há os viveiros, seguidos das praias El Huina e Punta Faro, onde, logo na frente, é representado um pescador utilizando vara (caña). No topo superior direito, estão os Morros Nidales, onde os pescadores estão pescando com espinhel. No canto direito, há a representação (de baixo pra cima) das praias e corregimentos de Mecana, Cocalito, Huaca, Playa Potes e Nabuga, em Mecana, onde os pescadores estão com linhas de mão, e em Nabuga com espinhel. Dessa forma, o mapa capta de forma simples toda a territorialidade local da pesca artesanal.

Figura 6 - Bahía Solano la pesca nos identifica

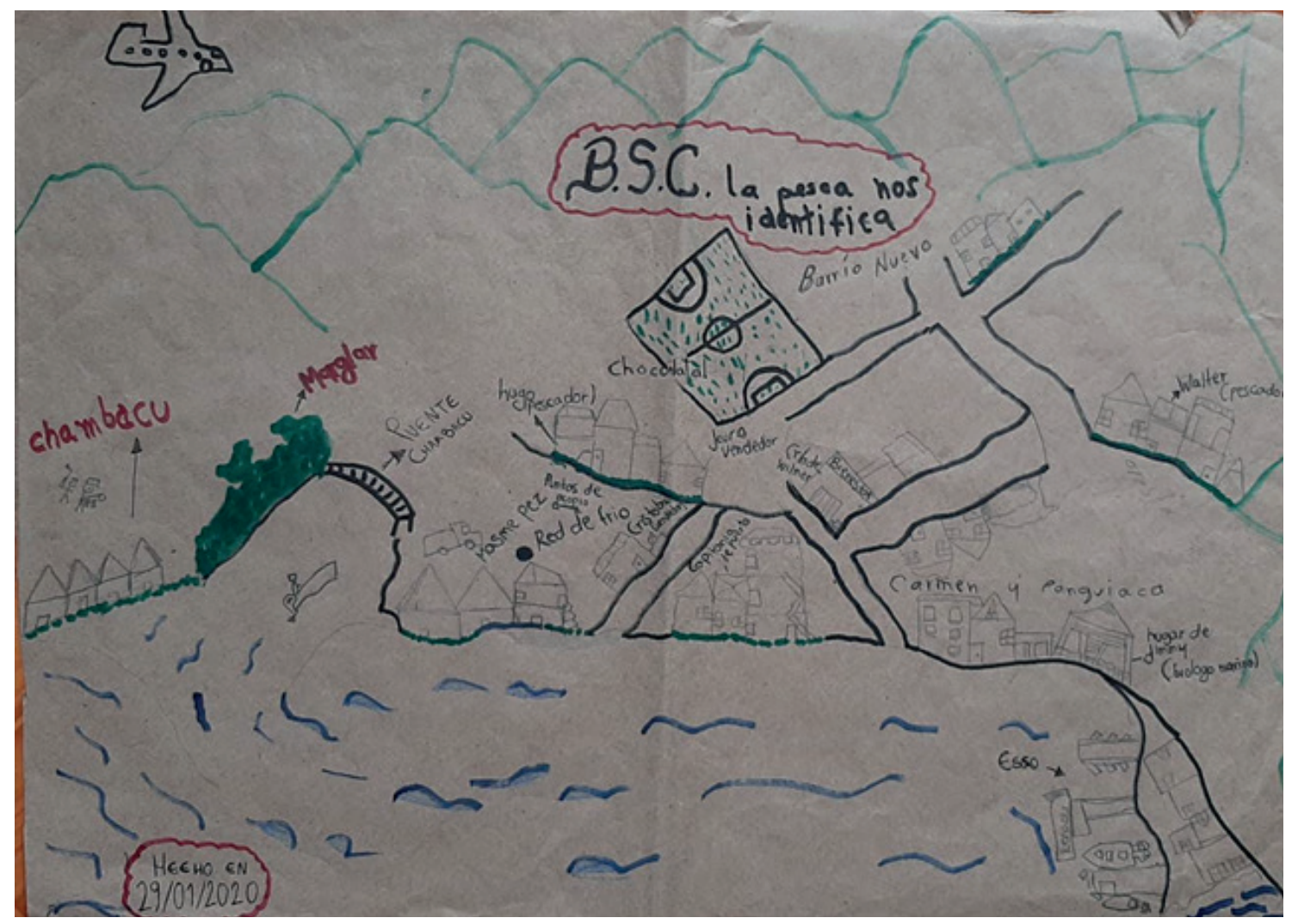

Fonte: Trabalho de campo (2020), elaborado pelos alunos do $10^{\circ} \mathrm{A}$, Maria Isabeth Gamboa Mosquera, Victor Daniel Lozano Berrio, Wilmer Andres Moreno Mosquera, Willian Rafael Sanelemente Rengifo, Juan David Poti Velasquez, em 29/01/2020. 
A figura 6 capta todo o território de Ciudad Mutis (sede municipal de Bahia Solano) e as territorialidades da pesca artesanal. No canto esquerdo, está o Bairro Chambacu com algumas pessoas trabalhando na agricultura ao lado do manguezal e da Ponte de Chambacu. Mas ao centro estão os "puntos de acopio" (pontos de comercialização), como a Red de frio, Masmepez e o comerciante Cristobal. Outros lugares representados também são: Captania de Puertos, casa do pescador Hugo, Bairro Chocolatal, Jairo (comerciante), Bienestar, Barrío Nuevo, casa do Walter pescador, hogar de Jimmy (casa do biólogo marinho da cidade), além do Esso (trapiche utilizado para embarque, desembarque e pequenas pescarias), com umas lanchas paradas, inclusive uma aparenta ser da marinha.

Figura 7 - Bahía Solano: pesca y cultura

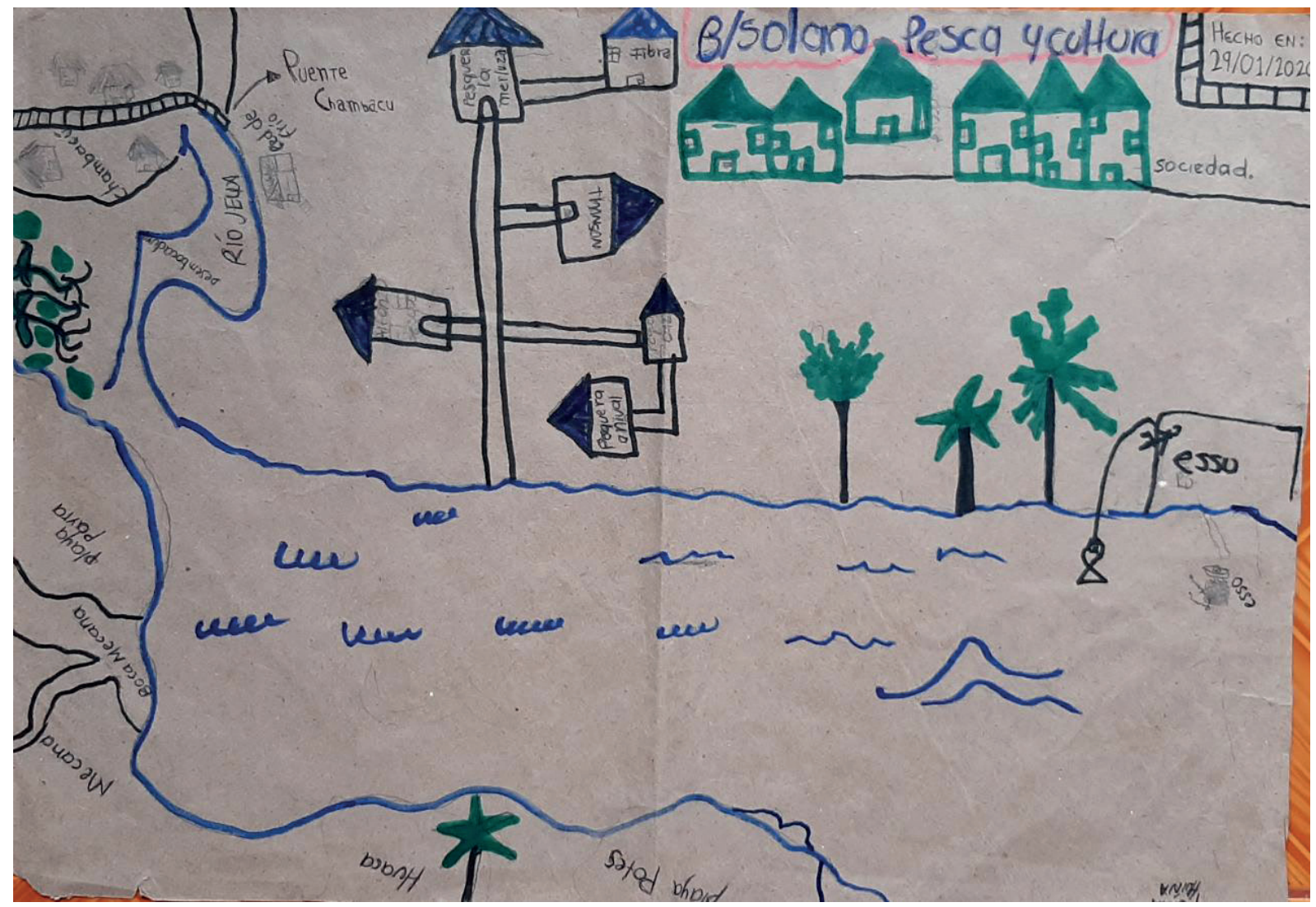

Fonte: Trabalho de campo (2020), elaborado pelos alunos do $11^{\circ} \mathrm{A}$ (nomes indisponíveis) em 29/01/2020.

Na figura 7, é representada toda a baía de Bahia Solano, sendo que, no canto inferior esquerdo, estão os corregimentos de Playa Potes, Huaca, Mecana, a Boca Mecana e a Playa payra. Está representada também a desembocadura do Rio Jella e todos os lugares que estão nessa territorialidade, como Chambacu e a ponte, a Red de frio, Merluza Pesquera. Na parte superior central, estão algumas casas que são lugares importantes para o circuito da pesca, e separado dessa parte está o que seria o centro da sede municipal, apresentado sob o título de "sociedad". No canto direito, está o Esso e um pescador pescando de linha. Bem abaixo há um escrito indicando Punta Huina, que se trata de outra praia de pescadores. 
Figura 8 - Zonas pesqueras de Bahia Solano

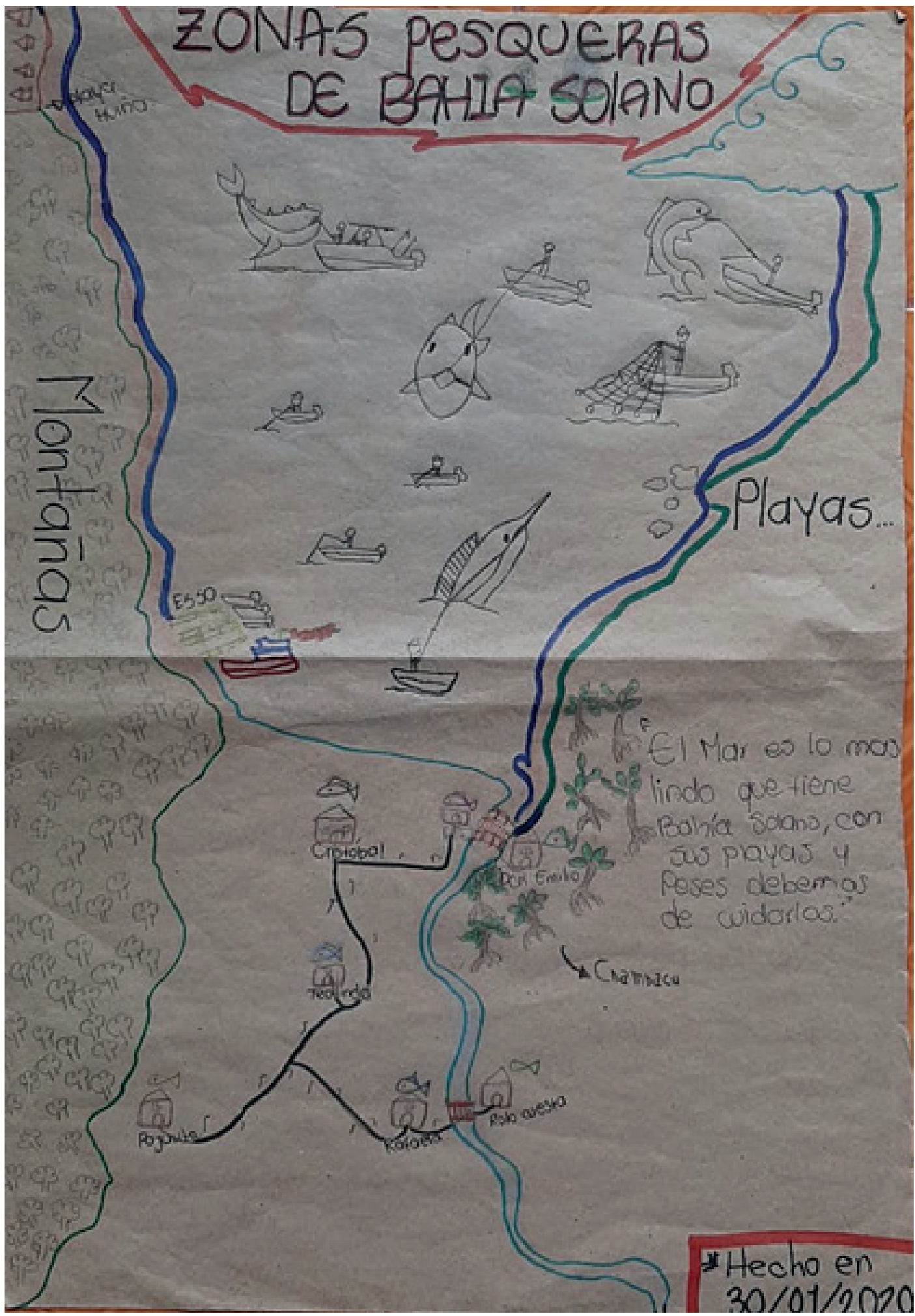

Fonte: Trabalho de campo (2020), elaborado pelos alunos do $9^{\circ} \mathrm{C}$, Estefania Pacheco, Enyimaria Moreno, Eileen Nicol Anchico Reiña, Manuela Aivathegui, Freddy Dias, em 30/01/2020 
A figura 8 dá destaque para a diversidade da fauna marinha e para a diversidade dos métodos de pesca e dos pescados. São representados a linha de mão, a tarrafa, o espinhel, as varas, e os diversos tamanhos de lanchas e de canoas. Entre a fauna marinha, identificam-se baleias, atum e peixe espada. Do lado esquerdo, estão as montanhas (serra), os lugares representados na parte que seria a cidade (parte mais central), identificada por Cristobal, Teolinda e a casa de Dom Emilio. É representada também a ponte de Chambacu e os manguezais presentes no bairro.

Figura 9 - Mapa de Bahia

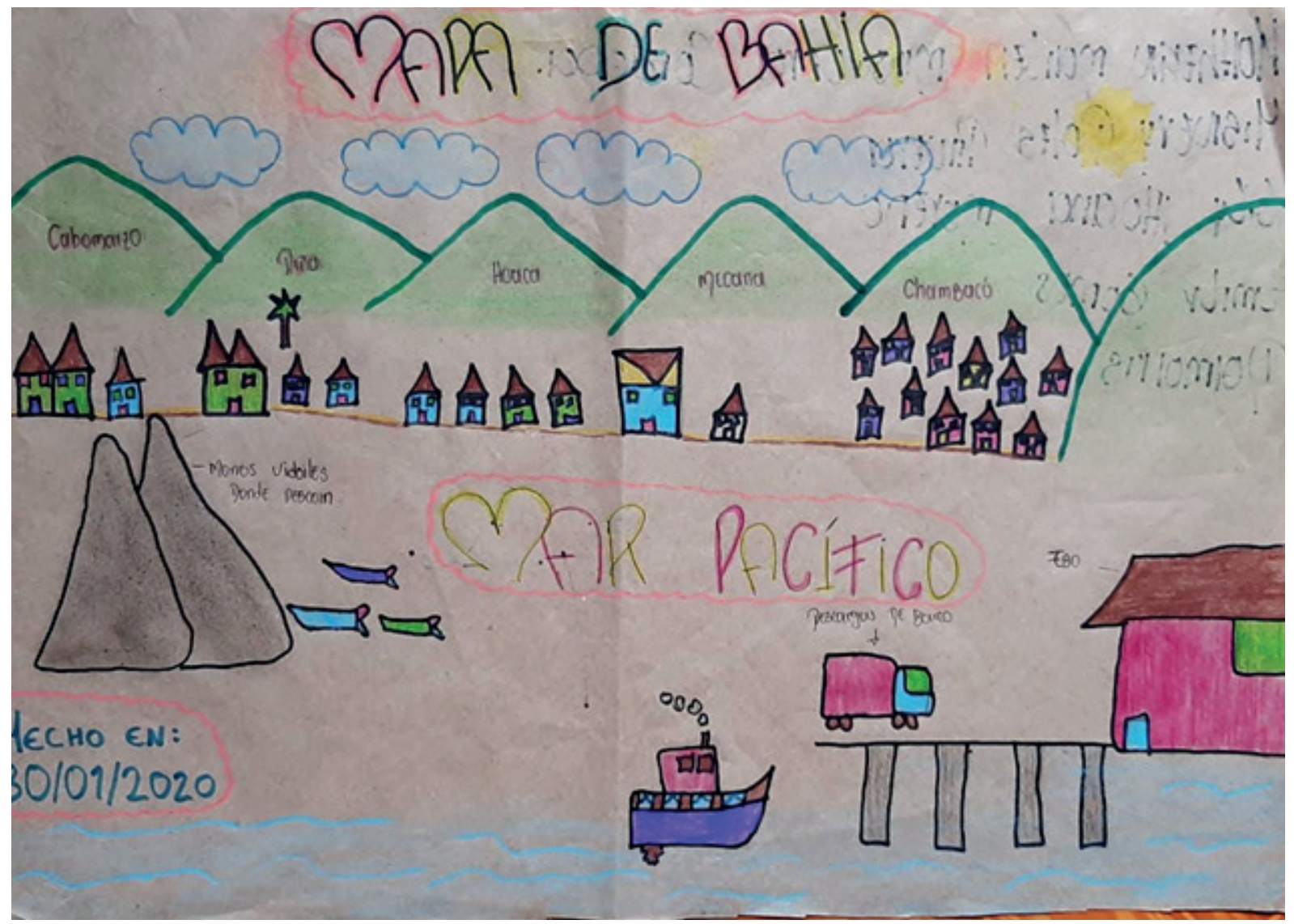

Fonte: Trabalho de campo (2020), elaborado pelos alunos do $9^{\circ} \mathrm{C}$, Katherin Mairlen Mosquera Cordoba, Yisnery Potes Rivera, Liby Jhoana Moreno e Emily Gomes, em 30/01/2020.

A figura 9 abrange, de maneira sucinta, a cidade de Bahia Solano e, mais ao fundo, as outras montanhas que seriam os corregimentos, sendo que cada montanha, assim, representa um lugar ou uma praia, Chambacu, Mecana, Huaca, Piña e Cabo Marzo (que já é município de Juradó). Também estão os Morros Nidales com três lanchas pesqueiras, além do posto Esso com um caminhão descarregando e com um barco de maior porte. A sede municipal (Ciudad Mutis) é representada por algumas casas. 


\section{6 - CONSIDERAÇÕES FINAIS}

A cartografia social participativa, praticada em oposição ao modelo hegemônico, como uma construção em que as relações de poderes foram transformadas a partir das visões dos sujeitos que estão inseridos nos territórios (ACSERALD; COLI, 2008) foi plenamente valorizada durante as oficinas realizadas no colégio da sede municipal de Bahia Solano, Instituición Educativa Luis López de Mesa.

Os sujeitos da pesquisa eram os alunos do colégio, cujos mapas construídos revelaram seus conhecimentos sobre os territórios e as territorialidades da pesca, dos quais são partícipes e conhecedores em sua grande maioria por se tratarem de familiares ou conhecidos de pescadores artesanais.

As ações e intervenções realizadas permitiram capturar a situação dos alunos como sujeitos conscientes da importância dos saberes e conhecimentos tradicionais e populares, capazes de formularem um senso político e crítico para os grupos de que fazem parte, bem como conscientes de suas apropriações do espaço, de suas territorialidades, pois como propõe Paulo Freire (1967), compreendemos a necessidade de fazer do homem ajustado, acomodado, um homem novo, um sujeito crítico. Daí a necessidade dos jovens identificarem e refletirem acerca das práticas tradicionais realizadas no território e das territorialidades construídas.

Assim, do conhecimento já existente sobre a pesca, os territórios e as suas territorialidades, procuramos, por meio das reflexões e das atividades, presentes nas oficinas, a promoção de uma aprendizagem ativa, em que os educandos também são sujeitos em seus próprios processos de ensino e de aprendizagem, possibilitando assim um intercâmbio de saberes entre todos os sujeitos envolvidos nas atividades, bem como um empoderamento a partir de seus próprios conhecimentos e práticas locais (PAULO FREIRE, 1967).

As oficinas foram realizadas também como uma maneira de fornecer alguma contribuição durante os dias em que estivemos em Bahia Solano, pois acreditamos que a pesquisa deve ser uma via de mão dupla e que não cabe somente ao pesquisador "extrair" os dados que lhe convém, mas sim, contribuir, de alguma maneira, para ampliar a compreensão de mundo no diálogo que se realiza. Tudo isso em busca de construir sociedades em que os sujeitos sejam menos Homo economicus e mais Homo politicus, conscientes, em favor do bem-estar social, do patrimônio histórico e cultural, da conservação e restauração ambiental dos espaços degradados de cada território (SAQUET, 2015).

Dessa forma evidenciou-se que o conceito de territorialidade está, sobretudo, ligado com as relações de parentesco, as práticas de trabalho e a toda uma configuração do lugar de reprodução do modo de vida, sendo que a cartografia social participativa se mostrou como uma ferramenta importante para fornecer uma articulação entre saberes e conhecimentos, por meio de uma linguagem acessível para a representação e discussão da realidade. 


\section{7 - REFERÊNCIAS}

ACSERALD, Henry; COLI, Luis Regis. Disputas territoriais e disputas cartográficas. In: ACSERALD, Henry. Cartografias Sociais e Território. Rio de Janeiro: IPPUR/UFRJ, 2008. p.13-43. Disponível em: http://www2.fct.unesp.br/docentes/geo/raul/cartografia tematica/leitura $\% 204 /$ Cartografias $\% 20$ Sociais\%20e\%20Territ\%F3rio.pdf Acesso em: 30/10/2020.

DANE, Departamento Administrativo Nacional de Estadística. Resultados Censo Nacional de Poplación y Vivienda 2018: Riosucio, Quibdó, Chocó. Bogotá: DANE, 2019. Disponível em: https://www.dane.gov.co/files/censo2018/informacion-tecnica/presentaciones-territorio/ 190806-CNPV-presentacion-Choco.pdf. Acesso em: 19/10/2020.

DÍAZ, Juan Manuel; CARO, Natalia. El mar como território y la pesca como actividad tradicional en el Pacífico Chocoano. In: DÍAZ, Juan Manuel; GUILLOT, Lía; VELANDIA, Manuel Camilo (orgs.). La pesca artesanal en el norte del Pacífico Colombiano: un horizonte ambivalente. Bogotá: Fundación Mar Viva, 2016. p. 29-43.

DÍAZ, Juan Manuel; GALEANO, Juliana. El entorno biogeofísico. In: DÍAZ, Juan Manuel; GUILLOT, Lía; VELANDIA, Manuel Camilo (orgs.). La pesca artesanal en el norte del Pacífico Colombiano: un horizonte ambivalente. Bogotá: Fundación Mar Viva, 2016. p.15-27.

ESCOBAR, Arturo. Territorios de la diferencia; Lugar, movimientos, vida, redes. 2.ed. Popayan: Universidad del Cauca, 2015.

FREIRE, Paulo. A educação como prática da liberdade. Rio de Janeiro: Paz e Terra, 1967.

HOOKS, Bell. Ensinando a transgredir; a educação como prática da liberdade. 2 ed. São Paulo: WMF Martins Fontes, 2017.

PELEGRINA, Marcos Aurélio. Cartografia social e uso de mapeamentos participativos na demarcação de terras indígenas: o caso da TI Porto Limoeiro-AM. Geousp - Espaço e tempo, v. 24, n. 1, p. 136-152, 2020. Disponível em: https://www.revistas.usp.br/geousp/article/ view/138814/160406. Acesso em 25/10/2020.

SAQUET, Marcos Aurélio. Por uma geografia das territorialidades e das temporalidades: uma concepção multidimensional voltada para cooperação e para o desenvolvimento territorial. 2.ed. Rio de Janeiro: Consequência, 2015.

SUZUKI, Júlio César. Território, modo de vida e patrimônio cultural em sociedades tradicionais brasileiras. Espaço \& Geografia, v.16, n.2, p.627-640, 2013. Disponível em: http://www. lsie.unb.br/espacoegeografia/index.php/espacoegeografia/article/view/272/197. Acesso em: 5/10/2020.

UMAÑA, Julio Carrizosa. Colombia compleja. Bogotá: Jardín Botánico José Celestino Mutis / Instituto de Investigación de Recursos Biológicos Alexander Von Humboldt, 2014. 